\title{
Terrestrial Applications of Extreme Environment Stirling Space Power Systems
}

\author{
R. W. Dyson
}

\begin{abstract}
NASA has been developing power systems capable of long-term operation in extreme environments such as the surface of Venus. This technology can use any external heat source to efficiently provide electrical power and cooling; and it is designed to be extremely efficient and reliable for extended space missions. Terrestrial applications include: use in electric hybrid vehicles; distributed home co-generation/cooling; and quiet recreational vehicle power generation. This technology can reduce environmental emissions, petroleum consumption, and noise while eliminating maintenance and environmental damage from automotive fluids such as oil lubricants and air conditioning coolant. This report will provide an overview of this new technology and its applications.
\end{abstract}

Index Terms-- acoustic devices, cogeneration, converters, distributed power generation, and temperature control.

\section{INTRODUCTION}

$\mathrm{E}$ XTREME environmental conditions including high temperatures and radiation fields have limited the range and duration of solar system exploration. This is due to the many practical limits encountered with electronics, instrumentation, materials, organics and other space vehicle components. While much progress has been made in the development of radiation hardened components, high temperatures are still a limiting factor. For example, as shown in Fig. 1, the surface of Venus exceeds $300^{\circ} \mathrm{C}$ and most power technologies either do not operate or are too inefficient to operate in that environment. On Earth, temperatures in volcanoes and deep sea drilling can also limit operations for many power systems.

Recently, NASA GRC began the development of a combined power and cooling system that is intended to operate in very high temperatures while providing the cooling protection necessary for sensitive components [1]. Specifically, three new Stirling Duplex systems were designed based on thermoacoustic, free-piston Stirling, and a novel free-displacer Stirling concept; a new extreme environment testing chamber was constructed for Technology Readiness Level 6 demonstration; a new five feature variable conductance heat pipe was demonstrated that enables multiple stops and restarts of the RPS system [2]; and a novel Stirling convertor with no moving parts was proposed.

These technologies can be directly applied to terrestrial

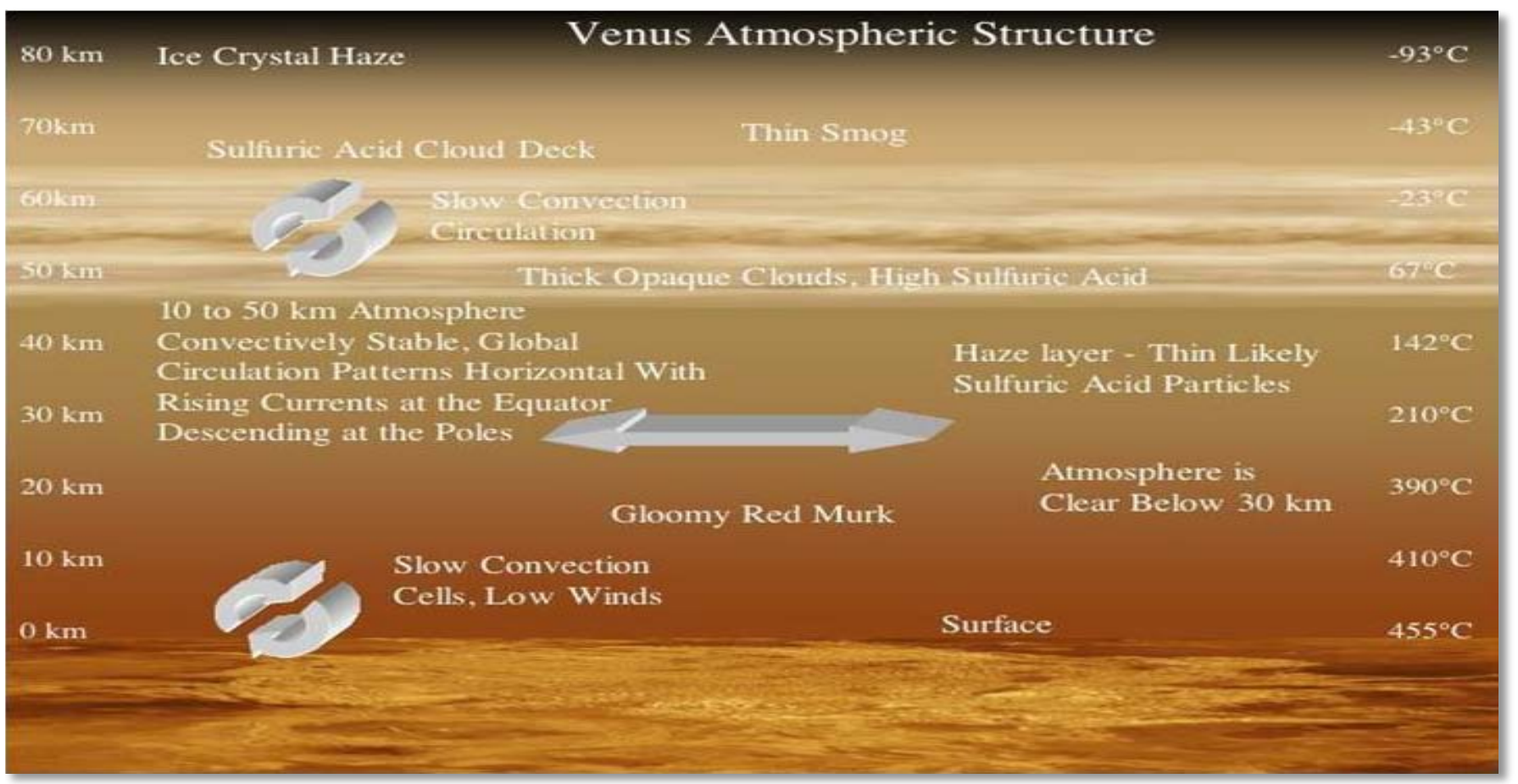

Fig. 1. Very high temperatures and cloudy conditions require specialized power and cooling system development for extended Venus surface missions.

R. W. Dyson is with NASA Glenn Research Center, Cleveland, OH 44135 USA (e-mail:Rodger.W.Dyson@nasa.gov) 
applications such as: use in electric hybrid vehicles; distributed home co-generation/cooling; and quiet recreational vehicle power generation. In space, the heat source for these technologies is typically nuclear and potentially solar. In the United States, the abundant supply of natural gas has encouraged the commercial development of these space technologies with natural gas as the heat source. However, any heat source including combustion of wood, solar, and geothermal could be considered for use with these technologies.

\section{POWER OPTIONS}

It is well known that the choice of power system technology for a spacecraft depends on the required power level and expected mission duration. The range of technologies includes solar, chemical, radioisotope, and nuclear fission. Complementing each of those power sources are a variety of power conversion options including photovoltaic, thermo-photovoltaic, thermionic, thermoelectric, regenerative fuel cell, Stirling, Brayton, and other static and dynamic energy conversion devices (see Table I).

TABLE I

\begin{tabular}{|l|c|}
\hline \multicolumn{2}{|c|}{ POWER OPTIONS ON VENUS (WITH $850^{\circ} \mathrm{C}$ HOT-END) } \\
\hline Power Technology & Efficiency on Venus, \% \\
\hline Free-Piston Stirling & 17 \\
\hline Free-Displacer Stirling & 15 \\
\hline Thermoacoustic Stirling & 13 \\
\hline Brayton/Rankine & 11 \\
\hline Segmented Thermoelectric & 4 \\
\hline Photovoltaic & $<1$ \\
\hline Thermionic & $<1$ \\
\hline
\end{tabular}

The table shows the estimated efficiencies of currently available technologies if the external environment is very hot or cloudy like it is on Venus. Notice that the Stirling cycle based technologies are typically more efficient than the alternative power options. This can be explained by noting the operation of the Stirling cycle approximates the ideal Carnot cycle as shown in Fig. 2.

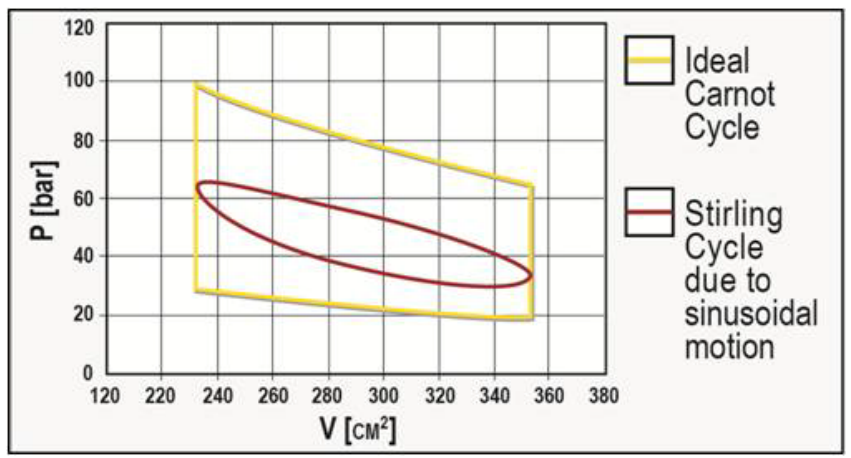

Fig. 2. Stirling engines are unique heat engines because their theoretical design efficiency approaches the theoretical maximum efficiency possible.

On Earth, all the power options listed perform better because of lower heat rejection temperatures and improved solar radiation frequency content and intensity. A similar comparison of cooling options also shows that Stirling cycle cooling tends to be the most efficient as well. A typical freepiston Stirling convertor configuration is shown in Fig. 3. It consists of two moving sections: an engine that converts heat to motion; and an alternator that converts motion into electricity.

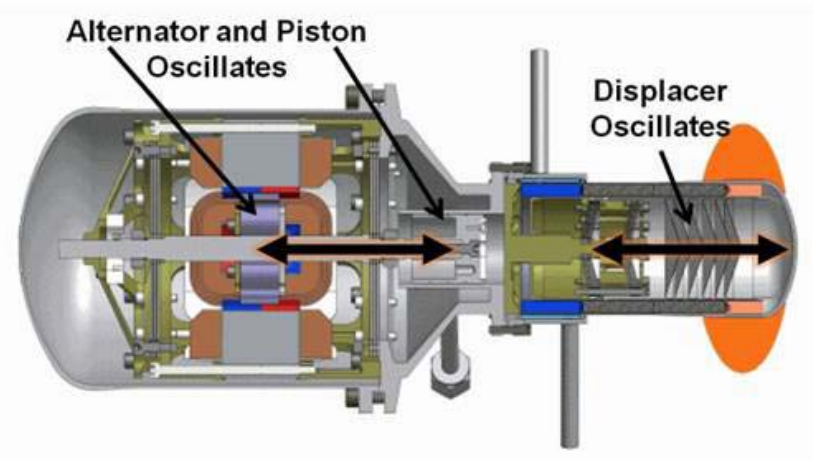

Fig. 3. Typical Free-Piston Stirling Configuration with two moving sections. (Courtesy Infinia Corp.)

The extremely hot environment on Venus not only reduces the efficiency of the Stirling convertor, but the materials used in the alternator are limited to operating in temperatures below $300^{\circ} \mathrm{C}$. Therefore, the alternator must be actively cooled. In addition, other components on the spacecraft require cooling including electronics, communications, and sensors. This combination of power and cooling is best achieved with a device in which the power and cooling are combined into a single device (Stirling Duplex) as shown in Fig. 4. Notice that in a Stirling Duplex that the top heat engine produces both electricity and mechanical energy for operating the cooler that is located on the bottom half of the figure.

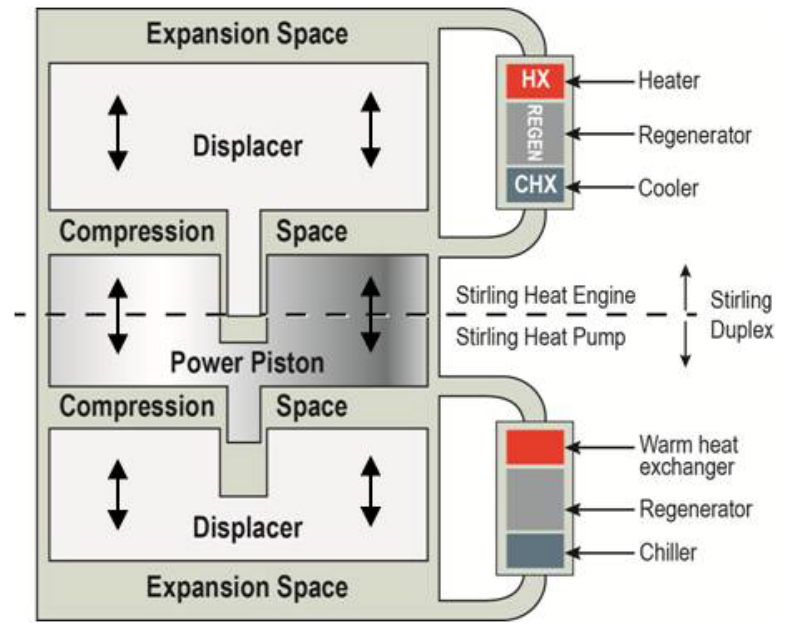

Fig. 4. Stirling power and cooling system combined into a single device. This combination of power and cooling is referred to as a "Stirling Duplex".

Since the temperature ratio on Venus is very small, both the power and cooling technologies must be extremely efficient. At the same hot-end temperature on Earth, the temperature ratio more than doubles-greatly increasing the efficiency. This high efficiency conversion performance makes these technologies attractive for terrestrial applications. 


\section{TeChNOLOgy DEVELOPMENT APPROACH}

An example Venus lander configuration is shown in Fig. 5.

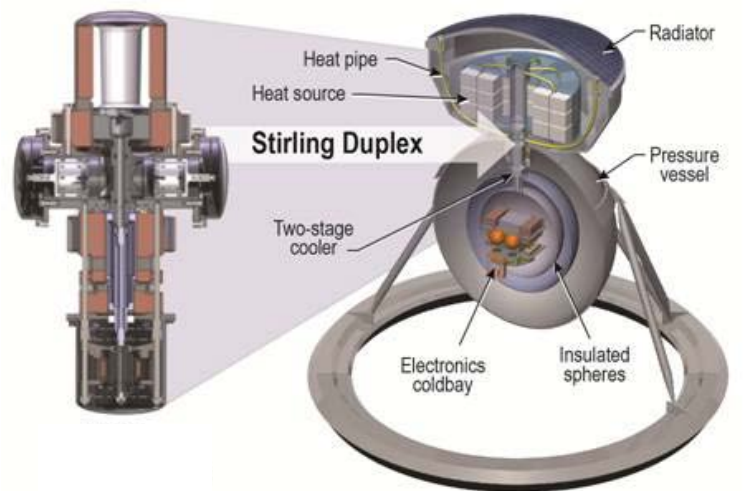

Fig. 5. Stirling Power and Cooling System in a Lander. Advanced Stirling Duplex (ASD) shown on left (courtesy Sunpower, Inc.)

In this configuration both the power and cooler are based on the Stirling cycle and two-stage cooling is employed [1]. The challenge for a location such as on the surface of Venus is to design a Stirling convertor that can operate at temperatures exceeding $1050^{\circ} \mathrm{C}$ on the hot-end in order to reduce the quantity of Plutonium-238 required (see Table II).

TABLE II

\begin{tabular}{|c|c|c|}
\hline \multicolumn{2}{|c|}{ POWER PERFORMANCE ON VENUS ( } & (500 ${ }^{\circ} \mathbf{C}$ Cold-End) \\
\hline $\begin{array}{c}\text { Hot-End } \\
\text { Temperature }\left({ }^{\circ} \mathrm{C}\right)\end{array}$ & $\begin{array}{c}\text { Power } \\
\text { Produced (We) }\end{array}$ & $\begin{array}{c}\text { Heat Input } \\
\text { Required (Wth) }\end{array}$ \\
\hline 1200 & 400 & 9247 \\
\hline 1200 & 50 & 2203 \\
\hline 1050 & 50 & 2679 \\
\hline 1000 & 5 & 1887 \\
\hline 950 & Not Possible & NA \\
\hline
\end{tabular}

At temperatures below $1050^{\circ} \mathrm{C}$, the Stirling Duplex cannot operate efficiently and temperatures above $1200^{\circ} \mathrm{C}$ are not currently possible due to material limitations. The heat lifted in the first case of Table I is $264 \mathrm{~W}$ and corresponds to the power and cooling required for a recently proposed flagship mission Venus lander. The remainder of the cases corresponds to a Stirling Duplex that is lifting 200W from a smaller lander with the goal of reducing the amount of Plutonium required. Notice that while the thermal to electrical efficiency seems low $(<5 \%)$, most of the energy is actually being used to cool the lander. Without the cooling requirement, the reported engine efficiency would exceed $20 \%$. And at a hot-end temperature of $950^{\circ} \mathrm{C}$ or lower the duplex cannot operate because the parasitic losses dominate.

The effect of hot-end temperature on thermal to electrical efficiency can be seen in Fig. 6 when cooling is not required. The definition of thermal to electrical efficiency used here is the ratio of electrical power output to gross heat input. Current Stirling convertors are limited to $850^{\circ} \mathrm{C}$ hot-end temperatures due to material limitations and cannot operate on Venus due to the high rejection temperature of $500^{\circ} \mathrm{C}$.

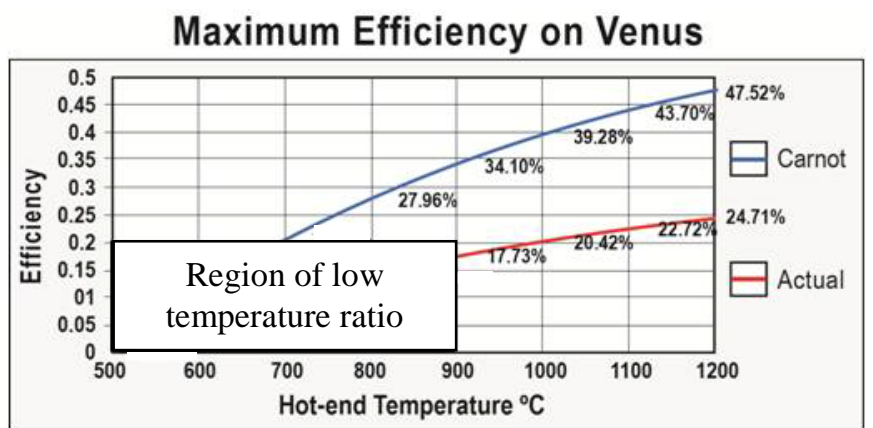

Fig. 6. The percent efficiency of a heat engine increases nearly linearly with hot-end temperature. Moreover, since the atmosphere is cooler $\left(20^{\circ} \mathrm{C}\right)$, the efficiency is nearly double that shown in this graph when the same technology is used for terrestrial applications. The region of low temperature ratio does not support Stirling Duplex operation.

Increasing the hot-end temperature can be achieved through the use of a novel single crystal super-alloy. As shown in Fig. 7, several of the Low Density Single Crystal (LDS) category super-alloys perform well at $1100^{\circ} \mathrm{C}[4,5]$, exceeding the performance of commercially available Nickel-based single crystal Rene' N5.

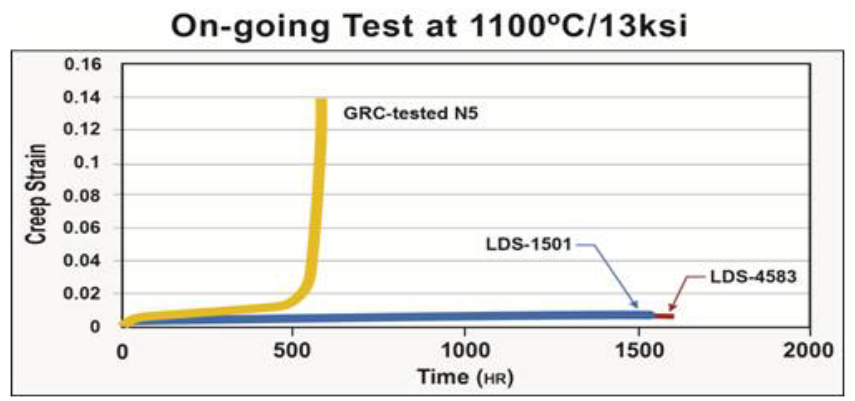

Fig. 7. High temperature heater head material creep strain performance. Note that LDS material is showing minimal creep strain at $1100^{\circ} \mathrm{C}$ and is a candidate heater head material for enabling efficient long-lived convertor operation. Commercially available Rene' N5 fails after 500 hours.

The advantage on Earth of using this new material is the thermal to electrical efficiency of the power conversion system can exceed $40 \%$. At these efficiencies, distributed home power production is commercially viable.

The Stirling convertor can be modified to eliminate moving parts in the hot-end, further increasing the potential efficiency as shown in Fig. 8.

Relative Heat Input vs. Head Temperature

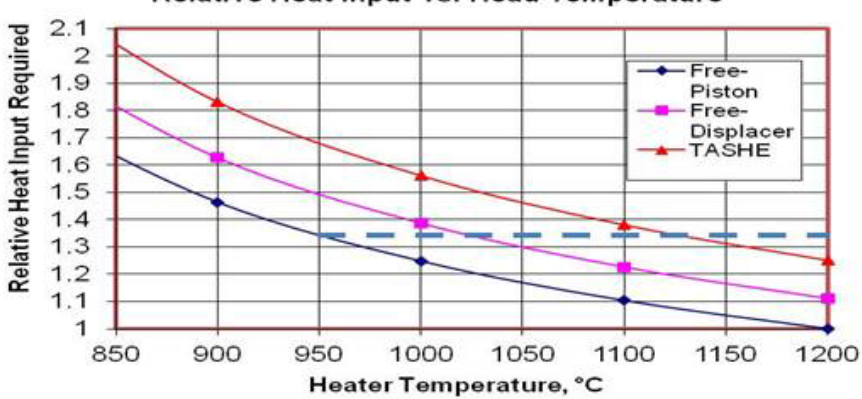

Fig. 8. The thermoacoustic Stirling heat engine (TASHE) exceeds the performance of a free-piston engine at higher hot-end temperatures with the assumption that free-piston engines cannot exceed $950^{\circ} \mathrm{C}$ due to having hot moving parts. Dashed line shows best performance of free-piston possible. 
Several such new engine configurations without moving parts in the hot-end have been recently demonstrated with low temperature prototypes and a full-scale high temperature design has been developed but not fabricated yet.

\section{PRototype HaRdWARE RESUlts}

Shown in Fig. 9 is a high power thermo-acoustic test rig [6]. It was designed to produce $4000 \mathrm{~W}$ of acoustical power operating at $30 \mathrm{~Hz}$ and with a hot-end temperature of $677^{\circ} \mathrm{C}$ and cold-end temperature of $27^{\circ} \mathrm{C}$. Initially the device did not meet performance expectations due to Gedeon losses through the jet-pump. But after properly rounding the jet pump holes the design goal of $30 \%$ was achieved. This configuration could be easily extended to higher efficiency performance by modifying the heater head material. At 30\% efficiency, this engine is a candidate configuration for distributed home power.

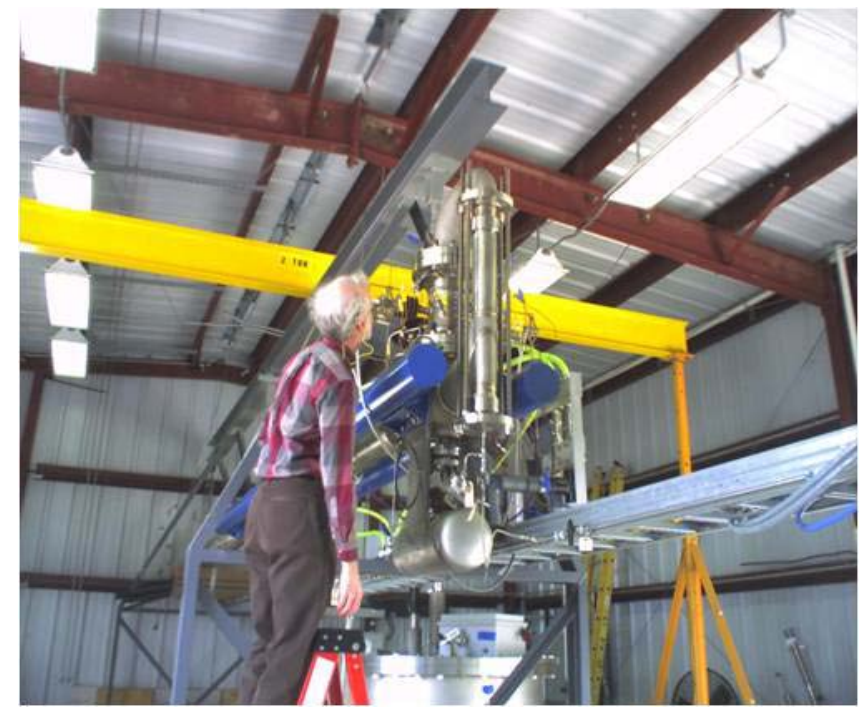

Fig. 9. Prototype thermoacoustic engine demonstrated $30 \%$ acoustical efficiency. (Courtesy Sierra-Lobo, Inc.)

A second concept demonstration engine was developed that is a hybrid configuration of a thermo-acoustic and free-piston Stirling engine. It was developed using similar technology as is currently used in the Advanced Stirling Radioisotope Generator (ASRG) [3], but it is designed to prevent the displacer from moving through the hot-end region of the engine. It also achieved over $30 \%$ efficiency with a hot-end temperature of $650^{\circ} \mathrm{C}$ and cold-end temperature of $30^{\circ} \mathrm{C}$ at 96 $\mathrm{Hz}$ (see Fig. 10).

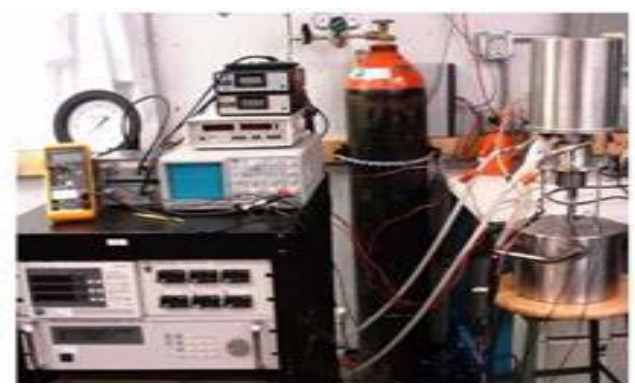

Fig. 10. Sunpower Free-Displacer Engine

These Stirling engine prototypes demonstrate that even at relatively low temperatures on the hot-end that they are efficient enough for home power production to be commercially viable. The challenge is to further reduce the per unit cost so that terrestrial uses are competitive with current technologies. In the next section a new design is proposed to reduce some of these costs by further reducing the mechanical complexity.

\section{STIRLING TECHNOLOGY IMPROVEMENTS}

One of the more significant developments in recent Stirling heat engine history has been the reduction in the number of moving parts required to achieve a Stirling power cycle. As shown in Fig. 11, the trend has been towards less mechanical complexity. The most recent concept is a no moving part Alpha Stirling Thermo-acoustically Resonated Electroacoustically Modulated ( $\alpha$-STREAM) Convertor shown on the bottom in Fig. 11.

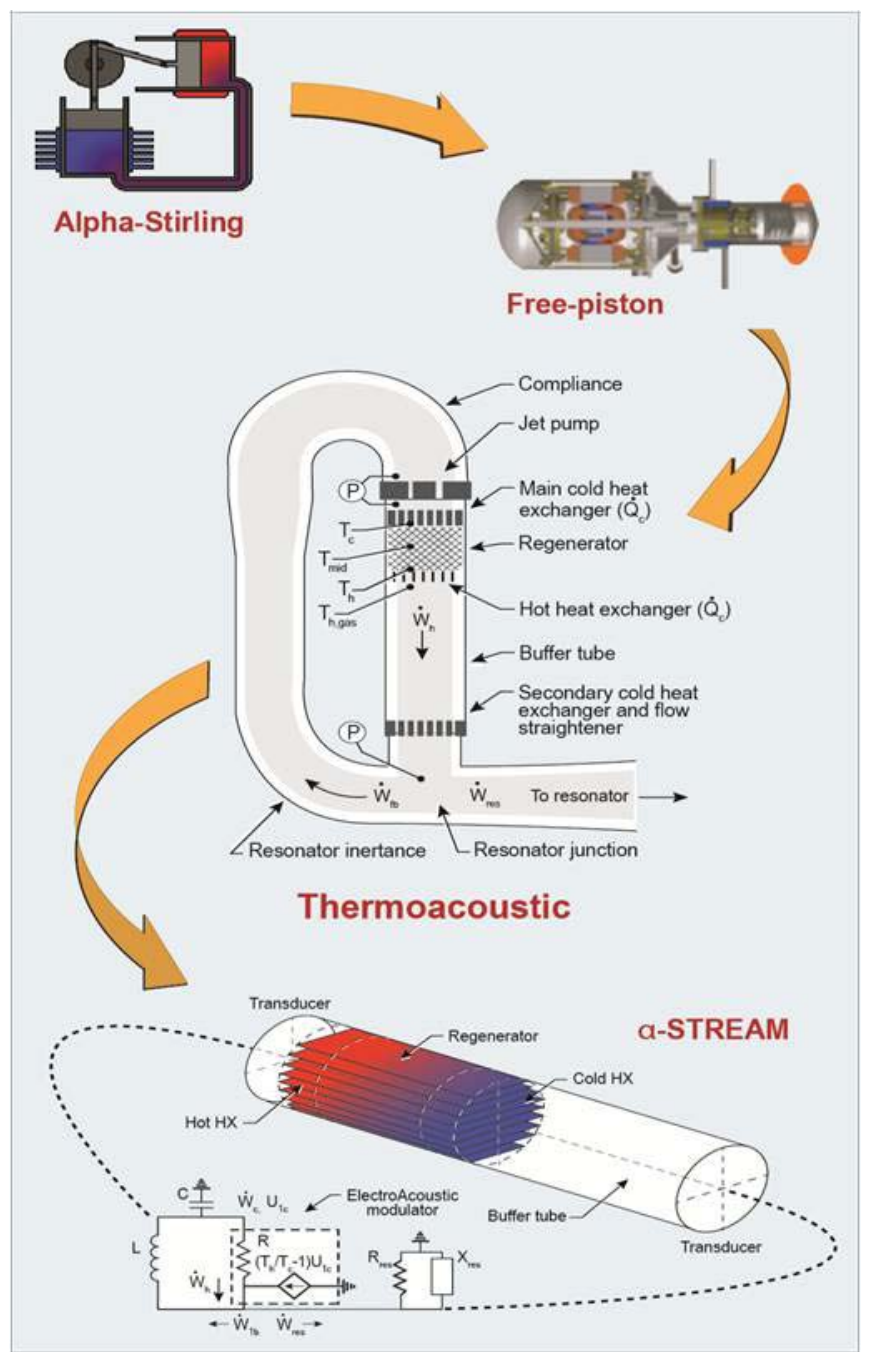

Fig. 11. Alpha-STREAM development path. The trend is toward fewer moving parts while still achieving over $30 \%$ thermal to electric efficiency.

\section{ALPHA-STREAM CONFIGURATION}

The main innovation of the $\alpha$-STREAM is reshaping the conventional thermoacoustic engine from a toroidal shape into a straight colinear arrangement and achieving acoustical resonance by using electronic components instead of mechanical components (i.e., inertance and compliance tubes). 
The acoustical wave that would normally travel around a toroid instead travels in a straight planar wave. This aspect is similar to existing cascade thermoacoustic engines, but this invention uses a transducer to receive the acoustical wave and then electrical components modulate the signal and a second transducer on the diametrically opposed side reintroduces the acoustic wave with the correct phasing to achieve amplification and resonance. The acoustic wave is allowed to travel in a virtual toroidal shape as before, but part of its path traverses an electrical circuit. This eliminates many of the parts and losses occurring in the current state of the art heat engines. Several early prototypes are under construction.

\section{CONCLUSION}

Extreme environment space exploration to hot locations requires the power and cooling systems presented in this work for extended in-situ operations. Moreover, the basic components for such a system have been demonstrated at low power and temperature. Even at relatively low hot-end temperatures, these new technologies show promise for terrestrial power grid applications because of their high efficiency and mechanical simplicity. Their thermal to electrical efficiency (>30\%) makes them competitive with current power grid delivery systems and several industrial groups are planning for the development of mass produced units for residential use. The challenge is to keep manufacturing costs low by reducing the number of complex components. Since thermoacoustic technology has been demonstrated and the closely related Alpha-STREAM engine concept further reduces component costs, the commercial prospects of this technology appear promising. Moreover, since space missions require highly efficient and reliable power systems, developing this technology contributes to both efforts.

\section{ACKNOWLEDGMENT}

The author gratefully acknowledges the contributions of members of his Advanced Stirling Duplex Team (http://www.grc.nasa.gov/WWW/TECB/extreme.htm).

\section{REFERENCES}

[1] R. W. Dyson, P. G. Schmitz, L. B. Penswick, and G. A. Bruder, "LongLived Venus Lander Conceptual Design: How to keep it cool," in Proc. 2009 AIAA $9^{\text {th }}$ International Energy Conversion Engineering Conf., AIAA 2009-4631, pp. 1-27.

[2] C. Tarau, W.G. Anderson, C.J. Peters, "Thermal Management System for Long-Lived Venus Landers", in Proc. 2009 AIAA $9^{\text {th }}$ International Energy Conversion Engineering Conf., AIAA 2011-5643, pp. 1-27.

[3] E.J. Lewandowski, J.G. Schreiber, "Testing to Characterize the Advanced Stirling Radioisotope Generator Engineering Unit”, in Proc. 2010 AIAA $10^{\text {th }}$ International Energy Conversion Engineering Conf., AIAA 2010-6693, pp. 1-11.

[4] F. Ritzert, M. Nathal, J. Salem, N. Jacobson, J. Nesbit, "Advanced Stirling Duplex Materials Assessment for Potential Venus Mission Heater Head Application”, in Proc. 2011 AIAA $11^{\text {th }}$ International Energy Conversion Engineering Conf., AIAA 2011-4631, pp. 1-27.

[5] R.A. MacKay, T.P. Gabb, J.L. Smialek, M.V. Nathal. US 7,261,783 B1 United States, 2007.

[6] M.S. Haberbusch, C.T. Nguyen, J.C. Ickes, G.W. Swift, "High-Power Thermoacoustic Stirling Heat Engine Results", in Proc. 2011 AIAA 11 ${ }^{\text {th }}$ International Energy Conversion Engineering Conf., AIAA 2011-5573, pp. 1-27.

\section{BIOGRAPHY}

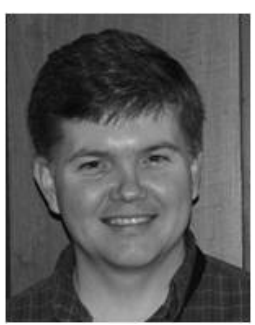

Rodger Dyson was born in Altoona, Pennsylvania. He graduated in 1990 from Hiram College majoring in physics, computer science, and mathematics. He later completed his Doctorate at Case Western Reserve University with a computational aeroacoustics thesis. His employment experience includes the United States Army National Guard, Allen Bradley Controls, Sverdrup Corporation, and NASA Glenn Research Center. Over his 22 year tenure at NASA he has published in the fields of high performance computing, aero-acoustics, and space power systems. He has recently invented a motionless energy conversion and a self-cleaning oscillating gas bearing check valve. His special fields of interest include high frequency oscillating energy conversion.

Dyson was recently featured in Wired.Com magazine, Wall Street Journal, and the BBC Radio 4 Today Program for the development of a unique Venus test chamber and a Stirling power system capable of surviving on Venus for extended durations. He was admitted to the Graduate Faculty at Cleveland State University. And he has recently attracted venture capital funds for the development of distributed home power from industry and academia. 